\title{
Viral shedders in a herd vaccinated against infection with bovine viral diarrhoea virus (BVDV) without prior testing for the presence of persistently infected animals
}

\author{
Mirosław P. Polak, Aleksandra Antos, Jerzy Rola, Jan F. Żmudziński \\ Department of Virology, \\ National Veterinary Research Institute, 24-100 Pulawy, Poland \\ ppolak@piwet.pulawy.pl
}

Received: September 23, 2016 Accepted: November 23, 2016

\begin{abstract}
Introduction: Bovine viral diarrhoea (BVD), caused by the bovine viral diarrhoea virus (BVDV), is one of the most important diseases of cattle worldwide. The purpose of the study was to determine the BVDV infection status in a dairy herd vaccinated against BVD. Before vaccination started in 2008, there had been no prior identification or the removal of the possible source of infection (persistently infected animals). It was expected that vaccination itself would enable the elimination of viral shedders on a long term basis. Material and Methods: Serological screening for antibodies against BVDV with determination for antibodies titres, BVDV antigen, and the presence of the viral genome with phylogenetic analysis of positive samples in the herd were performed, despite the lack of any clinical problems indicating possible presence of BVDV infection. Results: 19 individuals persistently infected with BVDV were identified among calves and heifers but not in adult cattle. All virus shedders were antibody negative and the genotype of isolated virus was BVDV-1b, indicating a single source of infection. The vaccine used in the herd was composed of BVDV-1a strain. In each of the tested cowsheds, antibody titres against BVDV-1b were higher than against BVDV-1a (median values). Conclusion: Despite a long-lasting vaccination programme and relatively high sequence homology of vaccinal and field strains of BVDV (83.6\%), it was not possible to avoid transplacental infections of foetuses and the birth of persistently infected calves from vaccinated heifers although the protection against clinical disease was accomplished.
\end{abstract}

Keywords: cattle, bovine viral diarrhoea virus, persistent infection, inactivated vaccine, cross protection.

\section{Introduction}

Bovine viral diarrhoea virus (BVDV) is a ubiquitous and diverse pathogen that affects cattle worldwide. It belongs to the genus Pestivirus within the Flaviviridae family. The infection caused by this virus is common, although the majority of animals are transiently infected with the subclinical course. Continuous presence of BVDV at the herd level is provided by animals persistently infected (PI) with the virus. Such individuals are generated after the transplacental infection of the foetus in the first trimester of pregnancy of PI mothers or seronegative females. The PI calves are born immunotolerant to BVDV and shed virus (in high titres) in body secretions and excretions throughout their life and they are the main source of infection within and among herds. PI animals are present in the herd at very low levels $(0.5 \%-2 \%)(10)$. Therefore, their identification is quite challenging and requires whole herd testing approach. Moreover, the genome of BVDV is a single-stranded RNA of positive polarity with a significant mutation rate, leading to the wide antigenic and genetic diversity of field strains. Two well-characterised species of BVDV, namely BVDV-1 and BVDV-2, are quite heterogeneous and within BVDV-1 species there are already 20 subtypes identified (from 1a to 1t) (7), while in BVDV-2 there are four subtypes at the moment $(2$, 4). In recent years an additional group of ruminant pestiviruses, first in foetal bovine serum (FBS) and then in live animals, was identified (17). This group is called Hobi-like viruses, atypical pestiviruses, or 
BVDV-3. Such a great diversity of BVDV strains indicates possible problems with laboratory diagnosis and possible failures of vaccination campaigns. To successfully control infection with BVDV at the herd level, cattle producers should implement key principles as described by Lindberg and Houe (14). These principles are: stringent biosecurity, detection and removal of PIs, continuous monitoring, and possible implementation of prophylaxis (vaccination). Prevalence of BVDV infection at herd level in Poland is high (12), while the genetic diversity of the virus is constantly increasing. The emergence of new genotypes every year has been reported $(12,13,16)$. Although the majority of vaccine producers declare sufficient protection from the postnatal infection and clinical problems due to BVDV, only a few vaccines provide foetal protection, at least according to manufacturer's data. However, incorrect use of vaccines (incorrect dose or route, failure in booster vaccination, contaminated equipment, interaction with other vaccines etc.), and lack of homology between vaccine and field strains of BVDV can lead to the lack or incomplete protection (15).

The aim of the study was to evaluate the BVDV status of a herd vaccinated against bovine viral diarrhoea (BVD) with an inactivated vaccine without prior testing for the presence of PI individuals.

\section{Material and Methods}

Animals. A dairy cooperative comprised 2480 animals in total. Milking cows and newborn calves until the age of six months were kept in four cowsheds (A, B, C, D). Heifers between 6 and 24 months were kept on two separate farms $(\mathrm{E}, \mathrm{F})$. They were inseminated at the age of 14-18 months, kept there until high pregnancy (last month of gestation), and then moved to four cowsheds for parturition. Animal movements were the following: heifers from A cowshed were transferred to $\mathrm{F}$ and back only, while heifers from B, C, and D were moved to E and back. Newborn bulls were sold to other farms or sent for slaughter within the first three months of life, but after birth they were kept in a separate location from females.

Vaccination against BVD was introduced in 2008. Prior to vaccination there had been no testing for the presence of PI animals. Primary vaccination with an inactivated vaccine containing BVDV-1a was implemented in heifers from the age of 12 months with a booster vaccination four weeks later. After arrival to cowsheds, all heifers were revaccinated. Cows in cowsheds A, B, C, and D were vaccinated every six months.

In 2012, an antigen ELISA for BVDV was performed, including all animals in A and $\mathrm{F}$ cowsheds and around $10 \%-15 \%$ of all animals in B, C, D, and E cowsheds (40-60 animals per farm). All results were negative.
In this study (testing accomplished in 2014-2015), all animals from six farms were screened with standard RT-PCR directed at 5'UTR region using pools of 20 serum samples. When a pool was positive, all samples in the pool were tested individually by antigen ELISA (IDEXX BVDV Ag/Serum Plus Test, Switzerland).

Detection of virus genome. Total RNA was extracted from serum samples using TRI Reagent (Sigma-Aldrich, USA) according to the manufacturer's instructions and stored at $-70^{\circ} \mathrm{C}$ until required.

One-step RT-PCR was performed using a Transcriptor One-Step RT-PCR Kit (Roche Diagnostics, Germany) according to the manufacturer's instructions using panpestivirus primers (20), which amplify a fragment of viral 5'UTR region and primers designed for amplification of partial $\mathrm{N}^{\text {pro }}$ coding region (19). The reaction conditions were set at $50^{\circ} \mathrm{C}$ for $30 \mathrm{~min}$ and $94^{\circ} \mathrm{C}$ for $7 \mathrm{~min}$, followed by 10 cycles at $94^{\circ} \mathrm{C}$ for $10 \mathrm{~s}, 53^{\circ} \mathrm{C}$ for $30 \mathrm{~s}, 68^{\circ} \mathrm{C}$ for $30 \mathrm{~s}$, and then 25 cycles at $94^{\circ} \mathrm{C}$ for $10 \mathrm{~s}, 53^{\circ} \mathrm{C}$ for $30 \mathrm{~s}, 68^{\circ} \mathrm{C}$ for $33 \mathrm{~s}$ with a final extension step at $68^{\circ} \mathrm{C}$ for $7 \mathrm{~min}$. RT-PCR amplicons of around 290 basis pairs were visualised by electrophoresis in $1.5 \%$ agarose gel in TAE buffer at $90 \mathrm{~V}$.

Real-time RT-PCR was used for some of positive serum pools. It was carried out using AgPath-ID Kit Reagents (Life Technologies, USA) according to the manufacturer's protocol in the StepOnePlus real-time PCR system (Life Technologies, Republic of Singapore). Specific primer pair and the probes for BVDV-1 and BVDV-2 genotypes within the 5'UTR viral genome designed by Baxi et al. (2) were used. The assay was run using the following thermal programme: $48^{\circ} \mathrm{C}$ for $10 \mathrm{~min}$ (RT-step), $95^{\circ} \mathrm{C}$ for $10 \mathrm{~min}$, and 40 cycles of $95^{\circ} \mathrm{C}$ for $15 \mathrm{~s}$ and $60^{\circ} \mathrm{C}$ for $45 \mathrm{~s}$.

Detection of antigen. BVDV antigen was detected by a commercial ELISA kit (BVDV Ag/Serum Plus, IDEXX, Switzerland). All samples with optical density (OD) values equal to, or above 0.3 were considered positive. This test provides a specificity of more than $99.7 \%$ and a sensitivity of nearly $100 \%$. PI status was confirmed by the second positive test applied three weeks after the first positive result, also using the antigen ELISA.

Detection of antibodies. The presence of BVDV antibodies in bovine serum was evaluated in PI individuals and in 20,38, 19, 24, 35, and 20 animals from $\mathrm{A}$ to $\mathrm{F}$ farms, respectively. Additionally, all mothers of PI animals were screened for antibodies. Serum samples were tested with $E^{\text {rns }}$-based Ab ELISA (BVDV Total Ab Test, IDEXX, Switzerland). Samples with $\mathrm{S} / \mathrm{P}$ values higher than or equal to 0.30 were classified as positive, those with values less than 0.20 were considered negative, and greater than or equal to 0.20 but less than 0.30 were considered suspect. All ELISAs were performed according to the protocols provided by the manufacturer and OD values were read at $450 \mathrm{~nm}$ wavelength.

Virus neutralisation test (VNT). It was performed on 42 random samples from heifers from 
BVDV-positive farms, on 14 samples from mothers of PIs (only five mothers were tested for both subtypes of BVDV), and on 12 samples from cows from BVDV-negative farm. Four mothers of remaining five PIs (one cow gave birth to twins) were not available for testing (one died and the remaining three were sent for slaughter due to other reasons). Two-fold serial dilutions (from 1:5 up to 1:3840) of serum samples with positive results in antibody ELISA were tested for neutralising antibodies against cytopathic (cp) BVDV1a strain Singer $(87.9 \%$ sequence identity with strain from tested herd) and noncytopathic (ncp) BVDV-1b Polish strain 60-GB/11 (97.4\% sequence identity with strain from tested herd). Bovine turbinate (BT) cells used for VNT were observed for five days for a cytopathic effect in the case of Singer strain, while the ncp biotype of the Polish field strain was detected by the indirect immunoperoxidase staining method with primary monoclonal antibody WB103/105 (APHA, UK), directed against NS2-3 protein. The antibody titres were determined as the reciprocal of the highest serum dilution, which neutralised the virus in at least $50 \%$ of the wells. Positive and negative control sera were included in each test run. Based on the results from cross-neutralisation tests, antibody concentrations at least four-fold higher than antibodies against other subgenotypes $(1 \mathrm{a} / \mathrm{lb})$ were considered subgenotype specific.

Phylogenetic analysis. Products from the standard RT-PCR were purified and sequenced as described previously (12). Resulting sequences of partial 5'UTR and $\mathrm{N}^{\text {pro }}$ regions were compared with the sequences retrieved from the GenBank using BLAST software (NCBI, NLM, USA) in a multiple sequence alignment performed using the CLUSTAL Omega software (18). To assess the sequences similarity for Polish strains, the reference strains from GenBank database and BVDV vaccine strain used in this herd were compared using BioEdit Sequence Alignment Editor (version 7.0.9.0) (9). Phylogenetic analysis was done by the neighbour-joining (NJ) algorithm with Kimura 2parameters using MEGA software (version 5.03). The reliability of the constructed phylogenetic trees was estimated by bootstrap analysis with 1000 replicates. Bootstrap figures greater than or equal to $70 \%$ have been presented. Nucleotide sequences of identified strains have been deposited in the GenBank database with the following accession numbers: for six sequences of 5'UTR region: KX853087 - KX853092, and for one sequence of $\mathrm{N}^{\text {pro }}$ region: KX853086.

Isolate genotyping. Restriction fragment length polymorphism (RFLP) was conducted as described previously (13) to determine the genotypes of the rest of the isolates from this herd (Fig. 3).

Confirmation of a PI status required that every positive sample (RT-PCR or antigen ELISA) in the first test was positive again at least three weeks later using antigen ELISA.

The statistical analysis was carried out using R 3.3.1 for Windows Software, which is an open source project that is distributed under the GNU General Public License. The Shapiro-Wilk test for normality, Spearman's rank correlation test, and Kruskal-Wallis rank test were used for data analysis.

\section{Results}

Overall, nineteen PI individuals were identified by RT-PCR and antigen ELISA in calves and heifers only. Additionally, testing with real-time RT-PCR confirmed the infection and demonstrated that the source of infection was BVDV-1. These animals were identified in farm B (seven animals), farm C (one animal), farm D (five animals), and farm $\mathrm{E}$ (six animals). PI prevalence at the herd level ranged from $0.24 \%$ on farm $\mathrm{C}$ to $1.5 \%$ on farm B. Heifers kept in farm F and cows with calves from farm A were negative. Acutely infected animals were not detected. All PI calves and heifers from farms $\mathrm{B}, \mathrm{C}$, and D had never been vaccinated while five out of six PIs from farm $\mathrm{E}$ had been vaccinated two or three times before testing (two vaccinations means priming at 12 months of age and booster three weeks later).

Antigen ELISA for all PIs had very similar values on both occasions for all animals (between 3.2 and 4.0 OD value) except for one heifer from farm $B$ in which the first reading was $2.29 \mathrm{OD}$ and in retest these values went up to 3.53 OD. This heifer was unvaccinated with a negative result in Ab ELISA. For two animals of unknown ages (from farms $\mathrm{B}$ and $\mathrm{C}$ ) a retest was not possible since the animals had been culled from the herd after the first positive result in antigen ELISA.

The youngest PI animals were identified on farm D (1-6 months) where three out of five PIs were seropositive in antibody ELISA. A sample from a onemonth-old calf from the same herd was doubtful for antibodies. The retest performed three weeks later gave negative results for all those samples except a twomonth-old calf of which was still positive with a similar OD value. A six-month-old PI heifer from this herd was seronegative on both occasions. PIs from other farms were also seronegative on both occasions except for two heifers on farm B. One heifer was weakly positive two times (at four months of age) and another one turned positive three weeks after initially doubtful result (at nine months of age). All mothers of PI progeny were positive in antibody ELISA.

Percentages of seropositive animals in all cowsheds (A-F) were 85, 98, 75, 87.5, 96, and 15 respectively. When the influence of the number of identified PI animals on the percentage of seropositive animals in all cowsheds were analysed, a strong correlation was found using Spearman's rank correlation test $(\mathrm{P}=0.01489$; rho $=0.8986)$. Additionally, significant differences were found in S/P ratios for tested animals among the cowsheds using Kruskal-Wallis rank test $(\mathrm{P}=1.289 \mathrm{e}-11)$ (Fig. 1). 


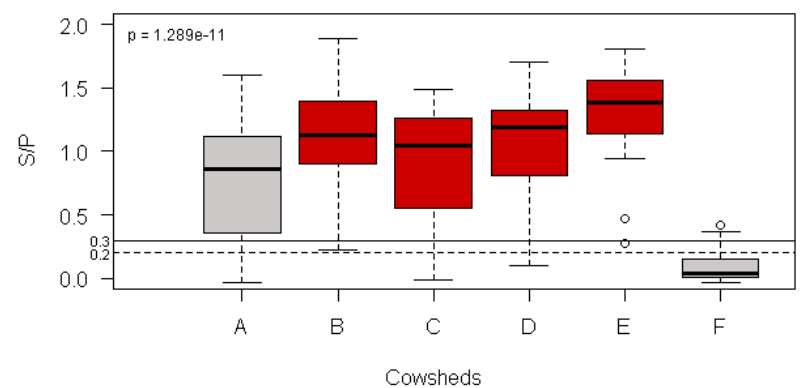

Fig. 1. Comparison of the S/P ratio (antibody ELISA) in the six cowsheds. Boxes which meant cowsheds where PIs animals were identified are coloured red. Box plots show medians (horizontal bar inside the box). Circles represent outliers. The dashed line is the cutoff value for the negative results, solid for positive, and the area between these lines corresponds with doubtful results



Fig. 3. RFLP analysis of the 5'UTR products of selected isolates from the tested herd. Line 1 - undigested amplicon; lanes $\mathrm{M}$ molecular weight marker (Fermentas - pUC19 DNA/MspI (HpaII); lanes 2, 3, 4, 5 - subtype $1 \mathrm{~b}$, tested samples of PI animals; lane 6 subtype 1f, digested positive control of amplification

When 42 serum samples were tested with VNT test, antibody titres at least four-fold higher against BVDV-1b, than BVDV-1a were identified in 22 samples, while only in 4 samples antibody titres were four-fold higher against BVDV-1a. Antibody titres against both subtypes were equal in 10 samples and the difference in antibody titres was less than four-fold in 6 samples. From 42 animals tested 33 samples were obtained with antibody titres less than 256 against BVDV-1a and 20 samples with titres below 256 against BVDV-1b. In tested mothers VNT titres ranged from 320 to 960 against BVDV-1a, and for each of five mothers VNT titres against BVDV-1b were 320 and the differences between titres against both subtypes were less than four-fold. In the farm where cows were vaccinated every six months, and where there were no BVDV-positive animals, antibody titres against BVDV-1a in eight samples were less than 256 (range from 30 to 240), while in four remaining animals the titres ranged from 480 to 3840 . Detailed results of serological assays are presented in Tables 1 and 2 .

Phylogenetic analysis revealed that the identity percentage among BVDV strains from the tested farms, based on 5'UTR region, was $100 \%$. Nucleotide sequences of 5'UTR (six isolates) region and $\mathrm{N}^{\text {pro }}$ (one isolate) were obtained from six animals, all from farm E. The nucleotide sequence analysis revealed that all isolates belonged to BVDV-1 subtype $1 \mathrm{~b}$, sharing the highest identity $98.5 \%$ with $60-\mathrm{GB} / 11$ isolate from Poland, 97\% with reference strain Osloss, $96 \%$ with vaccine strain VEDEVAC from Hungary, and 96\% with Manas-1 from China. The percentage identity between newly isolated strains and earlier Polish strains ranged from 93.4 to 98.5 for 5'UTR region and from 76.6 to 93.9 for $\mathrm{N}^{\text {pro }}$. The phylogenetic tree within 5'UTR comparing sequences of Polish isolates with the sequences of strains from GenBank database is shown in Fig. 2. The sequence similarity of the isolated strains (1b) and vaccine strain (1a) was $83.6 \%$ and $79.2 \%$ for 5'UTR and N ${ }^{\text {pro }}$ fragments, respectively.

RFLP analysis revealed that the rest of the isolates also belonged to the BVDV-1 subtype 1 b (Fig. 3).

Table 1. Distribution of positive animals, use of vaccination, positive results of antibody ELISA in percentages, and antibody titres against BVDV-1a and BVDV-1b in tested animals.

\begin{tabular}{|c|c|c|c|c|c|c|}
\hline Cowshed & $\mathrm{A}$ & B & $\mathrm{C}$ & $\mathrm{D}$ & $\mathrm{E}$ & $\mathrm{F}$ \\
\hline Number of PIs & 0 & 7 & 1 & 5 & 6 & 0 \\
\hline Ab-positive animals (\%) & 85 & 98 & 75 & 87.5 & 96 & 15 \\
\hline $\begin{array}{c}\text { Range of Ab titres against BVDV- } \\
\text { 1a (median) }\end{array}$ & $\begin{array}{c}30-3840 \\
(180)\end{array}$ & $30-1920(90)$ & $10-320(40)$ & $\begin{array}{c}30-3840 \\
(240)\end{array}$ & $20-160(80)$ & nd* \\
\hline $\begin{array}{l}\text { Range of Ab titres against BVDV- } \\
1 \mathrm{~b} \text { (median) }\end{array}$ & $\mathrm{nd}^{*}$ & $\begin{array}{c}30-1920 \\
(240)\end{array}$ & $\begin{array}{c}40->320 \\
(320)\end{array}$ & $\begin{array}{c}30-3840 \\
(320)\end{array}$ & $\begin{array}{c}160->320 \\
(320)\end{array}$ & nd* \\
\hline Vaccination & yes & yes & yes & yes & yes & yes \\
\hline
\end{tabular}

*nd - not done

Table 2. The distribution of BVDV-1a and BVDV-1b antibody titres in 42 tested animals from the cowsheds A, B, C, D, and E

\begin{tabular}{|c|c|c|c|c|c|c|}
\hline Antibody titre & $\begin{array}{l}\geq \text { four-fold higher } \\
\text { against } 1 \mathrm{~b} \text { than } 1 \mathrm{a}\end{array}$ & $\begin{array}{l}\geq \text { four-fold higher } \\
\text { against } 1 \mathrm{a} \text { than } 1 \mathrm{~b}\end{array}$ & $1 \mathrm{a}=1 \mathrm{~b}$ & $\begin{array}{l}\text { Difference less than } \\
\text { four-fold between 1a and } \\
1 \mathrm{~b}\end{array}$ & $\begin{array}{c}\text { Less than } 256 \\
\text { against 1a }\end{array}$ & $\begin{array}{c}\text { Less than } 256 \\
\text { against } 1 \mathrm{~b}\end{array}$ \\
\hline $\begin{array}{c}\text { Number of } \\
\text { samples }\end{array}$ & 22 & 4 & 10 & 6 & 33 & 20 \\
\hline
\end{tabular}




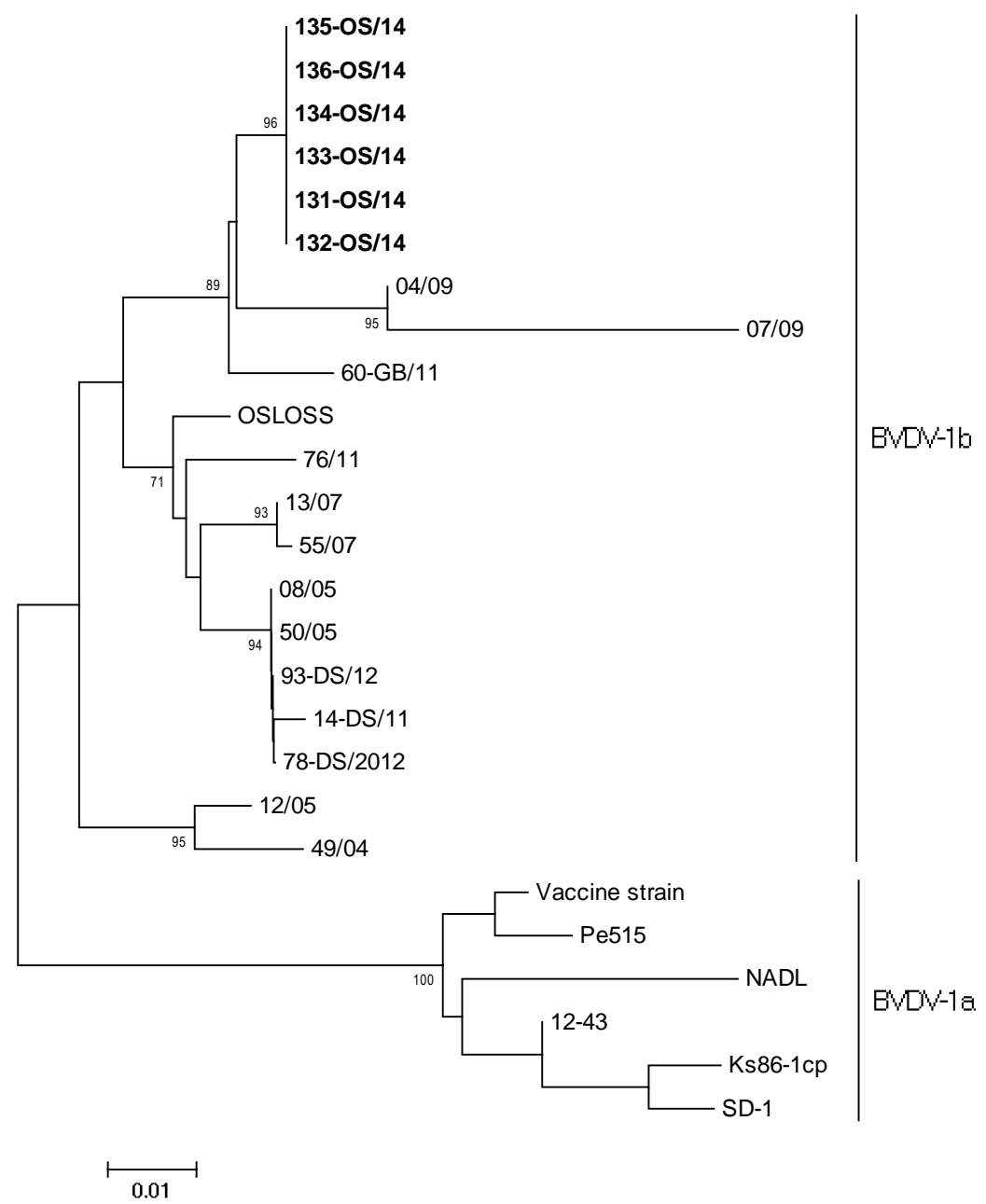

Fig. 2. Phylogenetic tree of Polish field isolates of BVDV-1b within 5'UTR region, created with neighbour-joining method and bootstrap test $(\mathrm{n}=1000)$ using MEGA software ver. 5.05. Isolates obtained from the tested herd are marked in bold. Numbers at branch nodes represent the percentage confidence levels. The scale shows the number of substitutions per position. Line brackets indicate subgenotypes within BVDV-1 species. Accession numbers from the GenBank database are the following: 04/09 (JN715000), 07/09 (JN715002), 60-GB/11 (JN715047), OSLOSS (M96687), 76/11 (JN715063), 13/07 (JN715006), 55/07 (JN715043), 08/05 (JN715003), 50/05 (JN715038), 93-DS/12 (Polish field isolate), 14-DS/11 (JN715007), 78-DS/2012 (Polish field isolate), 12/05 (JN715005), 49/04 (JN715037), Vaccine strain (EU180026), Pe515 (EU180025), NADL (AJ133738), 12-43 (AB359923), Ks86-1cp (AB078952), SD-1 (M96751)

\section{Discussion}

Prevention of PI animal generation is very important for the control of BVDV at farm level. PIs are considered to be the main source of infection for susceptible herdmates. Biosecurity and diagnosis are also important in virus spread control, which are additional measures to build the immunity to BVDV infection in the form of effective vaccination. Additionally, knowledge about the BVDV species and subtypes is important for control programmes. Vaccination will be effective only when it is carried out correctly and preferably after previous determination of BVDV infection status.

Identification of PI animals with BVDV-1b in this study suggests that maternal immunisation with BVDV-1a vaccine does not protect the foetuses from infection with antigenically distinct BVDV strain, despite the presence of high antibody titres in PI mothers. The lack of acutely infected animals in the tested farms can be explained by the fact that such animals develop viraemia which lasts for a few days only, followed by a clearance of the virus by the immune system due to seroconversion (11). It is most likely that the sampling was done after the seroconversion.

Our study confirmed the results obtained by Grooms et al. (8) who demonstrated that vaccinations with killed vaccine can significantly reduce the risk of foetal infection with BVDV in heifers continually exposed to PIs, but it does not give $100 \%$ protection from foetal infection and from the birth of PI calves. Lack of clinical symptoms in the tested herds is most likely the result of the presence of post-vaccination antibodies. However, it is contradicted by the data from the study by Bolin and Ridpath (3) where the value of 256 as the viral neutralisation titre was found to be critical for the prevention of clinical symptoms, and in our study in $78 \%$ of the samples tested we obtained titres against BVDV-1a lower than 256.

In contrast, only $47 \%$ of animals had antibody titres lower than 256 against BVDV-1b. This may 
indicate that the virus that had entered into the herd caused higher rate of seroconversion than the vaccinal strain. A strong correlation that has been found between the number of PI animals present and the percentage of seropositive animals can also confirm this observation. The fact that antibodies against BVDV-1b are not correlated with the vaccination is supported by the results obtained by Wang et al. (21). They described experimental infection with BVDV-1b after vaccination with killed BVDV-1a vaccine, and the results showed that antibody titres against vaccinal strain were 4.27-fold higher than BVDV-1b antibodies only after vaccination.

Previous studies $(5,6)$ have shown that BVDV strains of subtype $1 \mathrm{~b}$ are more prevalent than subtype $1 \mathrm{a}$ and are isolated more frequently from calves with respiratory problems (6). The majority of commercial vaccines include subtype 1a; some of them have also BVDV-2 component, which might improve their efficacy. Referring to the data about genetic variants present in Poland (12) the most common subtypes of BVDV are $1 \mathrm{~b}$ and $1 \mathrm{~d}$, and $1 \mathrm{a}$ subtype has never been detected, which is why the sole use of vaccines based on BVDV-1a is not recommended.

Regular vaccination of heifers could be a suitable tool for controlling the infection and minimising the economic losses caused by BVDV infection, but only when PI animals are removed from the herd beforehand. As our results have shown, vaccinationonly approach does not release the herd from the virus. The aim of vaccination should be the induction of immunity that offers protection against congenital infection, thus avoiding the emergence of new PI animals; moreover, it must be adapted to the genetic diversity of the virus in the region in which the vaccine is to be used.

Conflict of Interests Statement: The authors declare that there is no conflict of interests regarding the publication of this article.

Financial Disclosure Statement: The research and the article were financed with the funds of the National Veterinary Research Institute in Pulawy.

Animal Rights Statement: None required.

\section{References}

1. Barros S.C., Ramos F., Pauperio S., Thompson G., Fevereiro M.: Phylogenetic analysis of Portuguese bovine viral diarrhoea virus. Virus Res 2006, 118, 192-195.

2. Baxi M., McRae D., Baxi S., Greiser-Wilke I., Vilcek S., Amoako K., Deregt D.: A one-step multiplex real-time RT-PCR for detection and typing of bovine viral diarrhea viruses. Vet Microbiol 2006, 116, 37-44.

3. Bolin S.R., Ridpath J.F.: Assessment of protection from systemic infection or disease afforded by low to intermediate titers of passively acquired neutralizing antibody against bovine viral diarrhea virus in calves. Am J Vet Res 1995, 56, 755-759.
4. Flores E.F., Ridpath J.F., Eiblen R., Vogel F.S., Gil L.H.: Phylogenetic analysis of Brazilian bovine viral diarrhea virus type 2 (BVDV-2) isolates: evidence for a subgenotype within BVDV-2. Virus Res 2002, 87, 51-60.

5. Fulton R.W., Ridpath J.F., Confer A.W., Saliki J.T., Burge L.J., Payton M.E.: Bovine viral diarrhoea virus antigenic diversity: impact on disease and vaccination programmes. Biologicals 2003, 31, 89-95

6. Fulton R.W., Ridpath J.F., Ore S., Confer A.W., Saliki J.T., Burge L.J., Payton M.E.: Bovine viral diarrhoea virus (BVDV) subgenotypes in diagnostic laboratory accessions: distribution of BVDV1a, 1b, and 2a subgenotypes. Vet Microbiol 2005, 30, 35 40.

7. Giammarioli M., Ceglie L., Rossi E., Bazzucchi M., Casciari C., Petrini S., De Mia G.M.: Increased genetic diversity of BVDV-1: recent findings and implications thereof. Virus Genes 2015, 50, 147-151.

8. Grooms D.L., Bolis S.R., Coe P.H., Borges R.J., Coutu C.E.: Fetal protection against continual exposure to bovine viral diarrhea virus following administration of a vaccine containing an inactivated bovine viral diarrhea virus fraction to cattle. Am J Vet Res 2007, 68, 1417-1422.

9. Hall T.A.: BioEdit: a user-friendly biological sequence alignment editor and analysis program for Windows 95/98/NT. Nucleic Acids Symp Ser 1999, 41, 95-98.

10. Houe H.: Epidemiological features and economical importance of bovine virus diarrhea virus (BVDV) infections. Vet Microbiol 1999, 64, 89-107.

11. Howard C.J.: Immunological responses to bovine virus diarrhoea virus infections. Rev Sci Tech 1990, 9, 95-103.

12. Kuta A., Polak M.P., Larska M., Żmudziński J.F.: Predominance of bovine viral diarrhea virus $1 \mathrm{~b}$ and 1d subtypes during eight years of survey in Poland. Vet Microbiol 2013, 166, 639-644.

13. Kuta A., Polak M.P., Larska M. Żmudziński J.F.: Genetic typing of bovine viral diarrhoea virus (BVDV) by restriction fragment length polymorphism (RFLP) and identification of a new subtype in Poland. Bull Vet Inst Pulawy 2015, 59, 19-22.

14. Lindberg A., Houe H.: Characteristics in the epidemiology of bovine viral diarrhea virus (BVDV) of relevance to control. Prev Vet Med 2005, 72, 55-73.

15. Meadows D.: A study to investigate the use and application of BVDV vaccine in UK cattle. Cattle Practice 2010, 18, 202-215.

16. Polak M.P., Kuta A., Rybałtowski W., Rola J., Larska M., Żmudziński J.F.: First report of bovine viral diarrhoea virus-2 infection in cattle in Poland. Vet J 2014, 202, 643-645.

17. Schirrmeier H., Strebelow G., Depner K., Hoffmann B., Beer M.: Genetic and antigenic characterization an atypical pestivirus isolate, a putative member of a novel pestivirus species. J Gen Virol 2004, 85, 3647-3652.

18. Sievers F., Wilm A., Dineen D., Gibson T.J., Karplus K., Li W., Lopez R., McWilliam H., Remmert M., Söding J., Thompson J.D., Higgins D.G.: Fast, scalable generation of high-quality protein multiple sequence alignments using Clustal Omega. Mol Syst Biol 2011, 7, 539.

19. Toplak I., Sandvik T., Barlic-Maganja D., Grom J., Paton D.J.: Genetic typing of bovine viral diarrhoea virus: most Slovenian isolates are of genotypes 1d and 1f. Vet Microbiol 2004, 99, 175-185.

20. Vilcek S., Herring A.J., Herring J.A., Nettleton P.F., Lowings J.P., Paton D.J.: Pestivirus isolated from pigs cattle and sheep can be allocated into at least three genogroups using polymerase chain reaction and restriction endonuclease analysis. Arch Virol 1994, 136, 309-323.

21. Wang W., Shi X., Wu Y., Li X., Ji Y., Meng Q., Zhang S., Wu H.: Immunogenicity of an inactivated Chinese bovine viral diarrhea virus 1a (BVDV 1a) vaccine cross protects from BVDV $1 \mathrm{~b}$ infection in young calves. Vet Immunol Immunopathol 2014 , $160,288-292$. 